\title{
فعالية برنامج تدريبي في تنمية الصور الذهنية لدي الأطفال \\ ذوي اضطراب التوحد
}

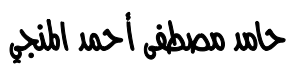

للمو اقف الماضية، وتعد الصور الذهنية إحدى

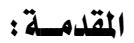

أدوات التفكير، وهى إما أن تكون صورة

لقد خلق الله (عز وجل) الإنسان

حسية أو لفظية، فإذا كنت نتظر الى وردي إنى فأحسن خلقة، وخلق له الحو اس لتستقيم حياته

أمامك فإن الوردة مدرك حسي وإذا أغمضت لفت

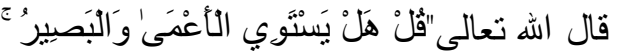
عبنك فإنلك نستطيع أن نراها أيضا، أي إنكا

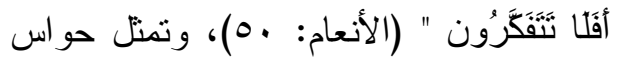
كونت صورة ذهنية عنها

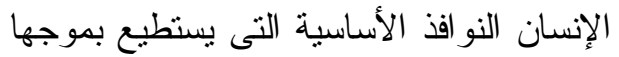

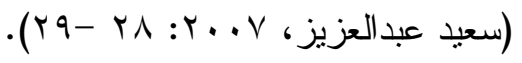

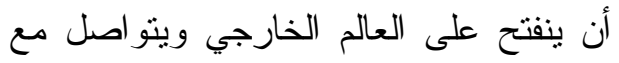
من أجل ذللك يرى الباحث ضرورة

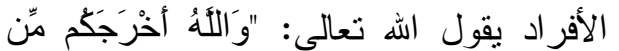
عمل برنامج تدريبي يعمل على نتمية الصور

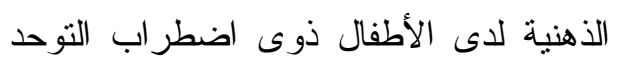

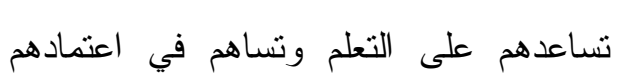
على أنفسهم فى أمور الحياة المختلفة.

\section{مشكلة الدراسة: - ماسل}

تتمثل مشكلة الدراسة فى أن الأطفال ذوي

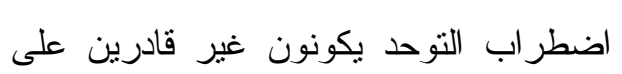

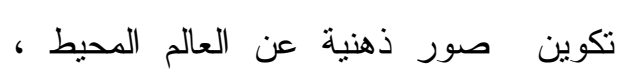

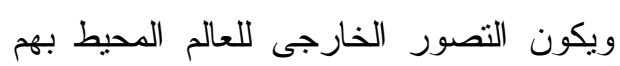

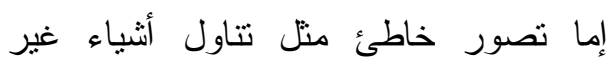
صالحه للأكل (كالحشب أو الورق) أو لا لأل يوجد تصور على الاطلاق (كعدم الاحساس

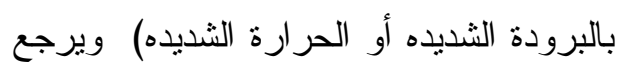
ذلك الى القصور الوظيفي فى عمل الحواس لديهم. ويرى الباحث اعداد برنامج تدريبي

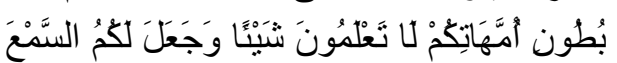

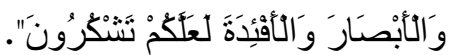

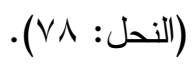

ويتضح أن العديد من الأطفال ذوي

اضطراب التوحد بتصفون بفرط الإستثارة الإنتقائية للمثير، أى أن الطفل بركز على لهن جانب واحد لشئ أو محيط، بينما يتجاهل

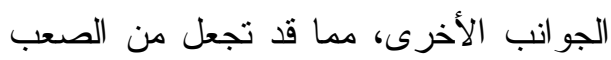
على الطفل ذوي اضطراب التوحد معرفة عالمة، لذلك فمن المهم مساعدتهم فى توجيه إنتباههم للجوانب ذات الصلة لشئ ما أو فئ تونه

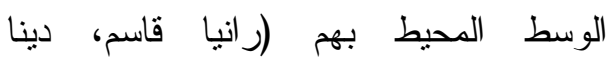
مصطفى، • (. r: (01). والصور الذهنية هي الصور التي لهي يسنطيع الفرد بواسطتها تصور الموقف هي الماضي عن الصور الحسية والصور اللفظية 
r- ايضاح العلاقة ما بين الحواس ودورها في تنمية الصور الذهنية لأطفال اضطر اب التوحد. - مئد

أهمية الدراسة:

1- التزايد المستمر فى أعداد الأطفال المصابين باضطر اب التوحد مما بستدعي ضرورة التذخل لمساعدة هؤلاء الأطفال. r- تقديم أداه مناسبة لقياس الصور الذهنية لدي أطفال اضطر اب التوحد.

r- التنخل لنقديم المساعدة والعون لأطفال

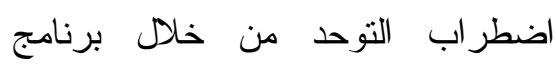
تدريبي يساعد على تتمية الصور الذهنية.

\section{المصطلحات الإجرائية:}

البرنامج التدريبي: هو خطة محكمة ومنظمة يتضمن مجموعة من الأنشطة المعتمدة

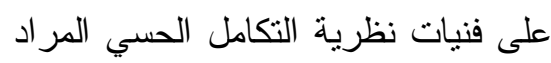

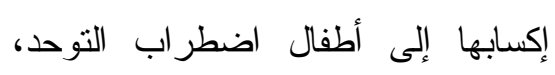
بهدف ثتمية الحواس ومن ثم مساعدتهم في تتمية الصور الذهنية عن البيئة و الو اقع الخارجي الذي يعيشو ا فيه.

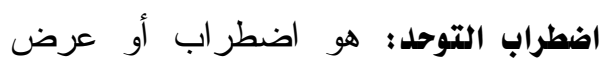
نمائي نظهر أعراض على الطفل قبل بلوغه سن (דا) شهر الأولى من عمره يصاحبه مشكلات سلوكية و اضطر ابات حسية تؤثز بشكل كبير على استقباله وجمعه للمعلومات من البيئة، مما يؤثز على حياته الاجتماعية، ويقاس بالدرجة
يعمل على تنمية الحواس من أجل بناء صور ذهنية صحيحة عن البيئة المحيطة بالطقل. ويمكن صياغة مشكلة الاراسة في السؤال الرئيس التالي:

ما فعالية برنامج تدريبي في نتمية الصور الذهنية لاي الأطفال ذوي اضطر اب التوحد؟ لهاب ويتفرع من السؤال الرئيس السابق الأسئلة التالية: 1- هل يختلف أداء أطفال اضطراب التوحد على مقياس الصور الذهنية في لفي القياس قبل تطبيق البرنامج و القياس بعد التطبيق ؟ r- هل يختلف أداء أطفال اضطر اب التوحد فى القياس البعدي عن أدائهم في لاءيط

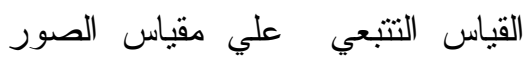

$$
\text { الذهنية؟. }
$$

أهداف الدراسة : تهلدف الدراسة الى: 1- نتاول اضطراب التوحد بالدراسة سعيا وراء الفهم، و القاء الضوء على مرحلة

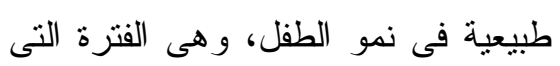
يتمركز فيها الطفل حول ذاتة. r- الكثف عن فعالية البرنامج التدريبي في دولي دئن

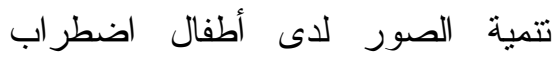
التوحد. 
ويعرفه (عبد العزيز الثخص، • ( • ب؟:

بأنr - Or

التو اصل و السلوك، بصيب الأطفال فى مرحلة

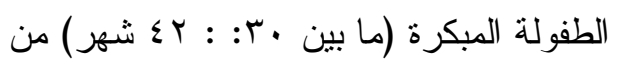
العمر ويؤثر فى سلوكهم ،حيث نجد معظم

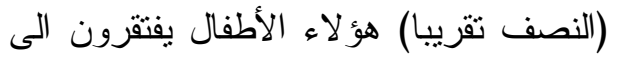

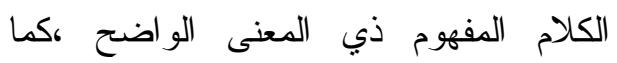

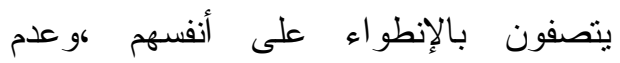

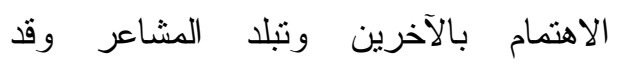
ينصرف اهتمامهم أحيانا الى الحيو انات، أو لأولئ الأشياء غير الإنسانية، ويلتصقون بها.

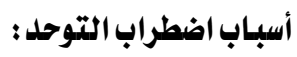

الأسباب النفسية:

يرى المؤيودن لوجهة النظر هذه أن

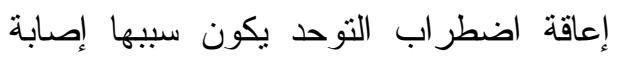
الطفل بمرض الفصام، الذى يصيب الأطفال في مرحلة مبكرة من عمر الطفل، ومع زيادة

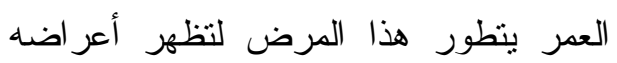

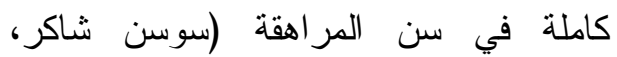
. (0. : : . . T

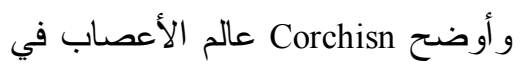
جامعة كاليفورنيا أن المشكلة تحدث بسهولة بعد الولادة حيث أن المخ يستمر في النمو

.(Holland, 2005: 87)

أسباب وراثية

ويدلل على ذلك ووجود انحر افات فى

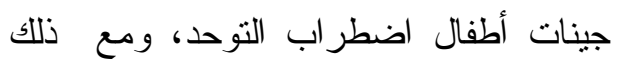

التى يحصل عليها الطفل في مقياس تشخيص اضطراب التوحد للأطفال

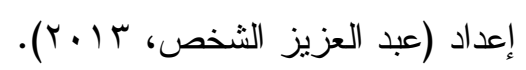
الصور الذهنية: هي تمثيل عقلي للأشياء الموجودة في البيئة المحيطة، بتخزين صورة ذهنية في الذاكرة عن الأشياء الحقيقية الموجودة في البيئة، من أجل

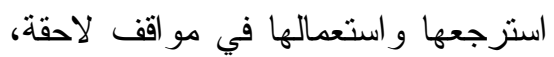
وتقاس بالدرجة التى يحصل عليها الطفل على مقياس الصور الذهنية لأطفال بلهال اضطر اب التوحد (إعداد الباحث). الإطار النظري اضطراب التوحد

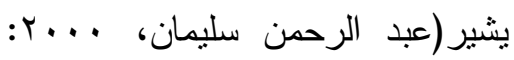

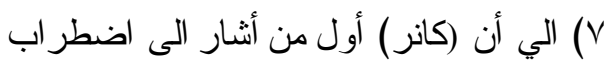

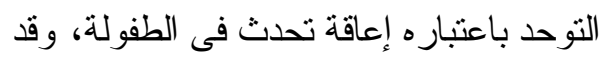
كان ذلك فى عام(1943) ، حيث أنه كان يقوم بفحص مجموعة من الأطفال المتخلفين عقليا

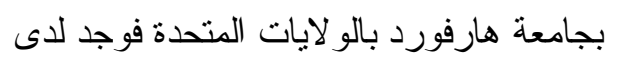
(1) طفلا مصنفين على أنهم متخلفين عقليا، مجمو عة من السلوكيات الغريبة والشاذة تعريف اضطراب التوحد : تعرفه منظمة الصحة العالمية: أنه اضطر اب نمائي يظهر فى السنوات الثلاثة الأولى من عمر الطفل، ويؤدي إلى عجز فى في لئى

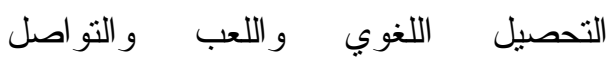
الإجتماعي. (Kendall, 2000: 77). 
فلا يوجد جين واحد مسؤول عن حدوث (فصام الطفولة،اضطراب ريت، و واضطراب

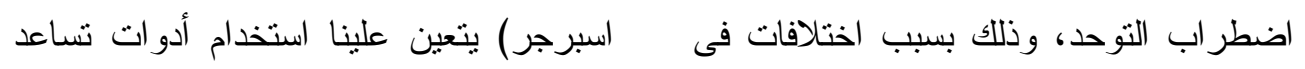

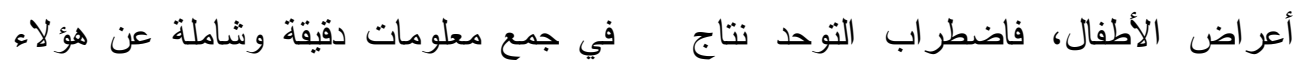

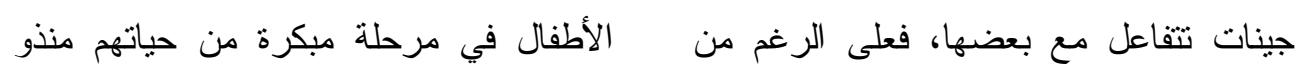

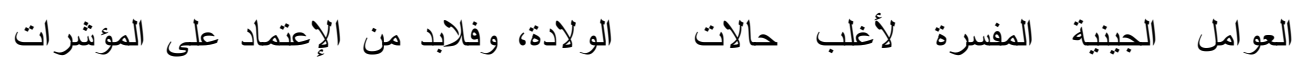

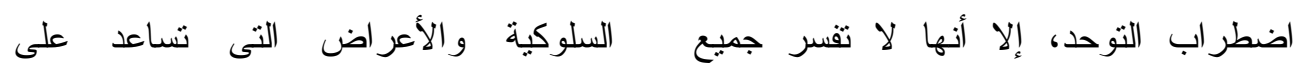

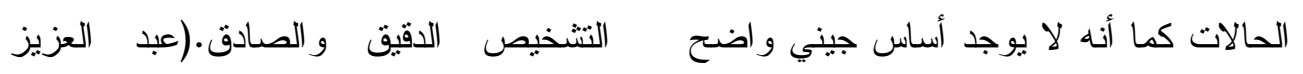

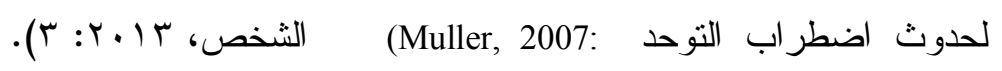
خصائص الأطفال ذوي اضطراب التوحد : $.90)$

\section{الخصائص العقلية والمعرفية :}

يعاني الأطفال ذوي اضطر اب التوفئ

من عيوب معرفية ومن نقص فى الاقتراب

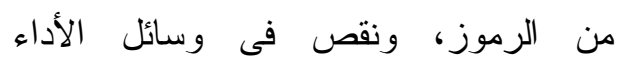

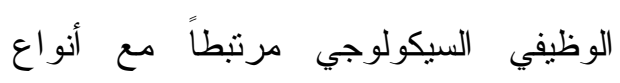
مرضية من السلوك، وبشكل خاص فى تجنب الحملقة، و النشاط الزائد و وغياب التعبيرات

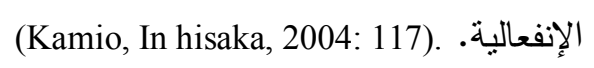

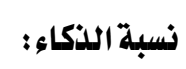
نجد أن ·ء\% من أطفال اضطراب

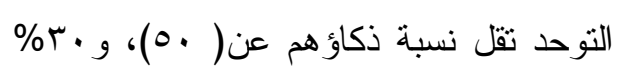

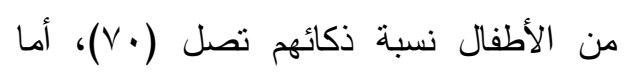

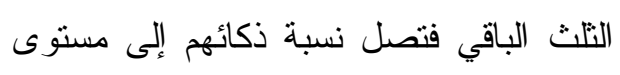

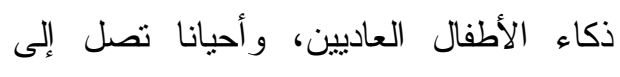
مستوى العباقرة (فوزية الجلامدة، نجوى حسن، سا •r

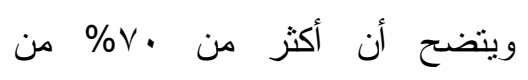
الأطفال ذوي اضطر اب التوحد لديهم قدرات وتعد الأسباب البيئية من أقدم وجهات

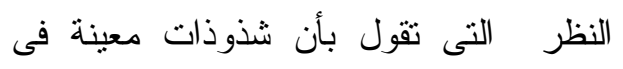
شخصية الأم وطريقة نربية الأم للطفل تهيئ

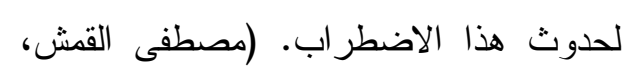
(r) $(r \cdot 1)$

\section{وجهة النظر التفاعلية:}

ونجد أن الأسباب سابقة الذكر تنقى

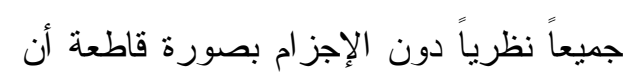

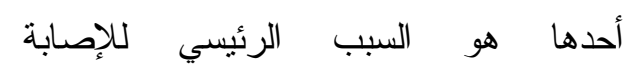
باضطراب التوحد ويرى اصحاب وجهة النظر التفاعلية أن السسب في لئ حدوث اضطر اب التوحد يكون في اجتماع الأسباب

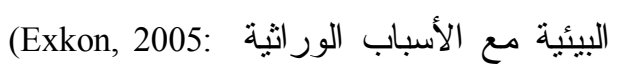

إن اضطر اب التوحد من الاضطر ابات النولئ

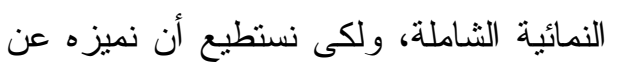

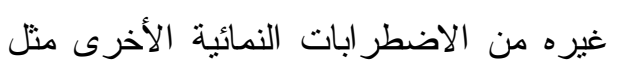


1- عمومية المعرفة لتحسين الإستراتيجيات

المستخدمة وزيادة النزكيز على حركات

معينة.

r- خصوصية المعرفة؛ وهى زيادة التركيز

على حركات معينة من المهارة.

ץ- تعميم الإثارة الدافعية لنتظيم الإسنتارة

و الحفاظ عليها.

ـ - الوصول إلى مستوى التمكن من الدافعية

العامة لزيادة الثقة بالنفس والإحتفاظ

$$
\text { بإتجاه إيجابي نحو الأداء. }
$$

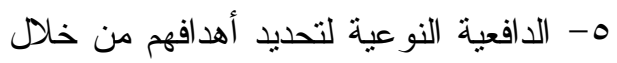

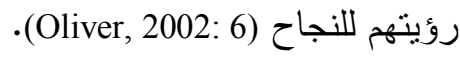

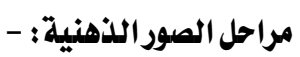

مراحل تكوين الصورة الذهنية التى حددها

كما يلى: (Piaget, 1975: 414-415)

1 - مرحلة تأسيس وتبلور الصور الذهنية، من الميلاد وحتى أربع سنوات.

و هي تقابل مرحلة الذكاء الحسي الحركي لدئوات وني

وقد ذكر بياجيه مجموعة من المؤشرات ندل

$$
\text { على تبلور الصورة الذهنية. }
$$

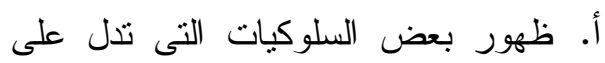

تكوين الوظيفة الرمزية مثل لعب الطفل

بالحيوان مقلداً صوت ذلك الحيوان، فيدل

ذلك على أنه قام بتكوين صورة ذهنية

$$
\text { لذلك الحيوان. }
$$

ب.السلوكيات التى نظهر لهدى الطفل أثناء

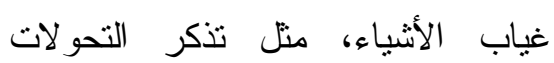

عقلية متدنية تصل أحيأناً إلى حدود الإعاقة

العقلية، في حين أن حو إلى · ( \% منهم تكون

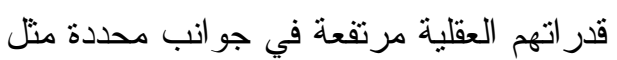

الذاكرة، الحساب، الموسيقي و الفن، كما يظهر

الأطفال ذوي اضطر اب التوحد مشكلات في

الإنتباه و النتشت، و النشاط الز ائد، وعدم القدرة

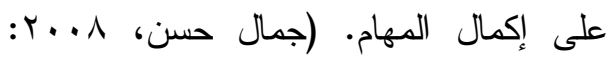

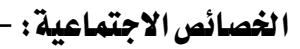

إن الصفة الإكلينيكية الأساسية

لاضطر اب التوحد: هى اضطر اب عميق فى الإنى

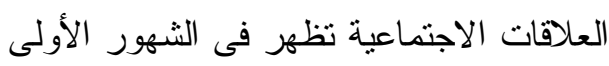

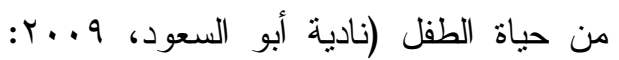

ويعد التوحد أيضاً اختلال دماغي يؤثز

بشكل كبير على قدرة الطفل على التواصل

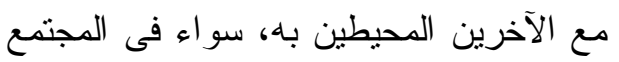

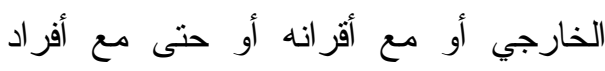
أسرته وكذلك فى علاقاته بهم، و الإستجابة

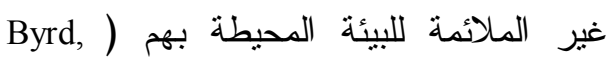
Sage, Keyzer, Shefeling, Gee, a Enders, .$(2000: 2$

\section{الصور الذهنية: - الن}

تعريف الصور اللذهنية:

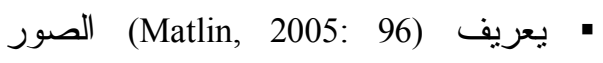
الذهنية بأنها تمثيل عقلى لشئ ليس له وجود طبيعي. 
المتعاقبة، أو إعادة بناء تحولات غير ويقوم العقل البشري بالإحتفاظ بآثار للحوادث

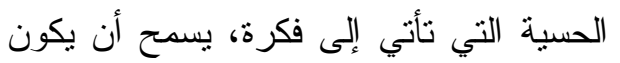
مدركة.

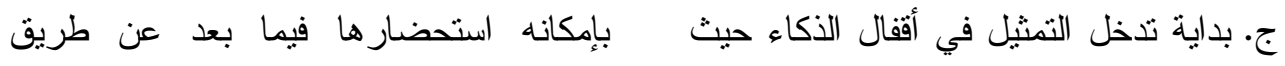

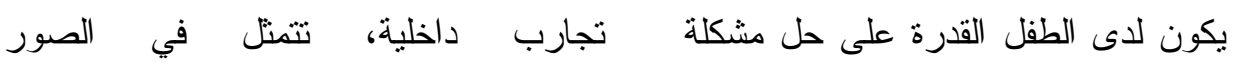

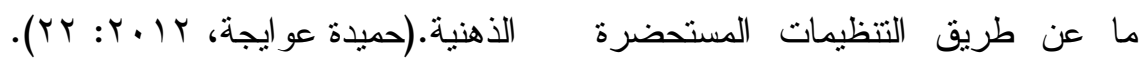
وتنقى الصورة الذهنية في مخ الإنسان للعقل. معتمدة على خبر اته السابقة منذ لحظة الميلاد الإنسان بإحتفاظه بصور ذهنية عن الأثياء

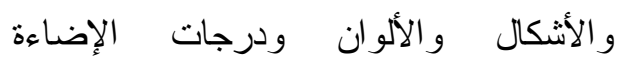
وهي ثقابل مرحلة الذكاء الحدسي أو ودرجات الحس المختلفة من خشن وناعم

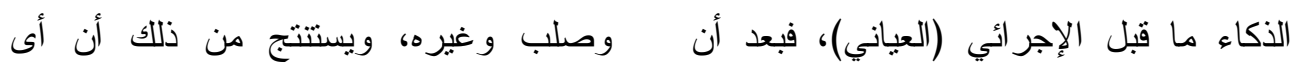

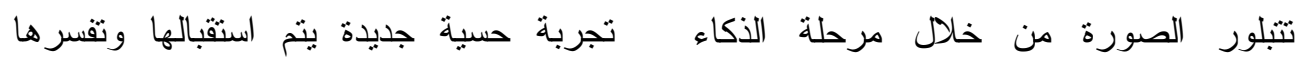

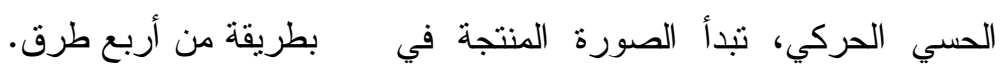

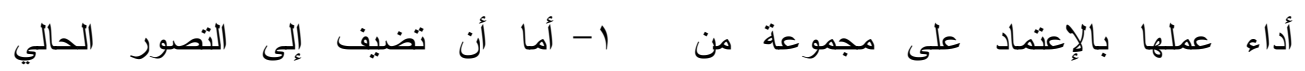

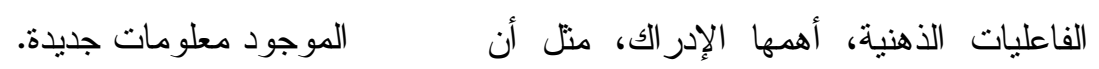

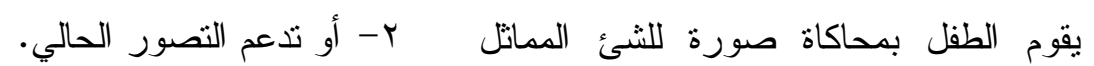

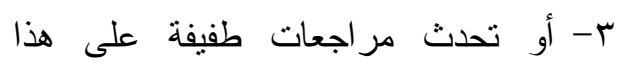

$$
\text { التصور . }
$$

ع- أو ينتج عنها إعادة بناء كامل للتصور.

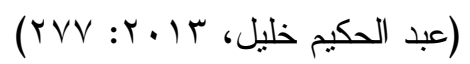

r- مرحلة الصور المنتجة الساكنة (الصور ما قبل الإجرائية) من أربع سنوات الصنه التى

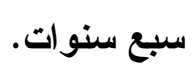

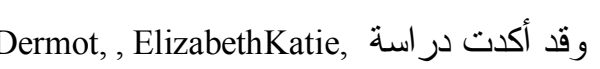
على أهمية الذاكرة العاملة (Marina (2014):

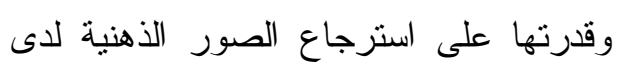

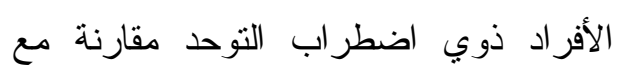
العاديين، وأثنارت النتائج الى تعزيز مفهوم الاعتماد التعويضي على استر اتيجيات مختلفة r- مرحلة الصور المنتجة أو التوقعية

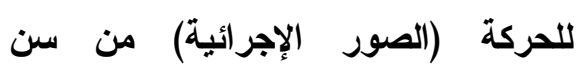
السابعة أو الثامنة، وفي هذه المرحلة تصبح حواس الطفل قادرة على إنتاج التوقع المصور الذى بسمح بإعادة تكوين

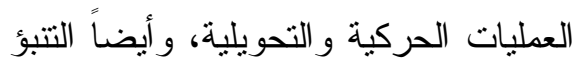
بالتعاقبات الجديدة، وهي نرنكز على نوقع مختلف التغيرات التى قد تلحق بالثئ أو تركئ بحدث ما. في تعلم الأشخاص ذوى اضطراب التوحد، 
وهى الاعتماد على الصور الذهنية والذكاء الحالية، فإنه يمكن صياغة فروض الدراسة

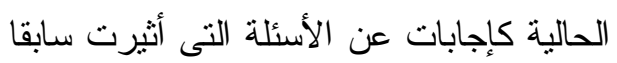

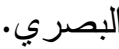

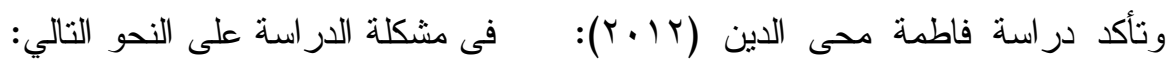
على فاعلية البرنامج التدريبي في لإثاء

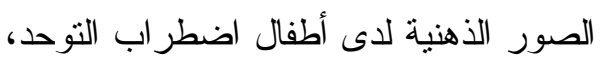

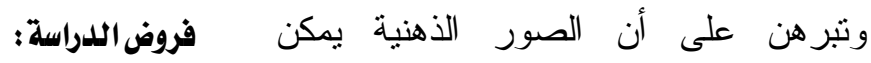
ا - توجد فروق دالة احصائيا بين متوسطات تتمياتها من خلال التدريب. رتب درجات أطفال المجموعة التجريبية على مقياس الصور الذهنية في القياس القبلي و البعدي لصالح القياس البعدي. r- لا توجد فروق دالة احصائيا بين متوسطات رتب درجات أطفال المجموعة التجريبية على مقياس الصور الذهنية في القياسين البعدي و التتبعي.

\section{الإجراءات المنهجية لللدراسة :}

\section{منهج الدراسة}

تم استخدام المنهج التجريبي(ثبه

التجريبي) لملاءمتة لموضوع الدراسة،

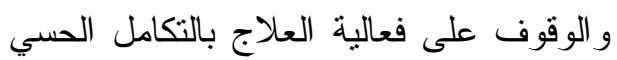
فى تتمية الصور الذهنية لأطفال اضطراب التوحد، وقد استخدم الباحث تصميم المجموعة الواحدة (القياس القبلي البعدي)، وتم الاعتماد على هذا التصميم وذلك لندرة العينة وصغر حجمها(محمود منسى وسهير كامل، سا بr:

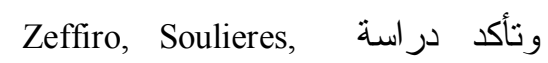
(على أهمية (Girard, Mottron, 2011): تكوين الصور الذهنية لدراسة العمليات البصرية العليا لدى المصابين باضطراب التوحد مقارنتا مع العاديين وتوصلت الدر اسة الى أن أطفال اضطراب التوحد كانوا أكثر دقه في تتكيل الصور الذهنية وكذلك تفوقوا في التمنيلات العقلية البصرية و التفكير لهنير المصور، و وتفوق المشاركين الأخرين في الاقة و السرعة و التصور العقلي الصحيح.

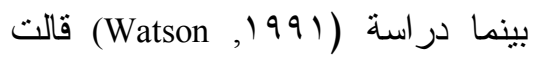
بأن أفضل الطرق لتكون الصور الذهنية هى لئه إستخدام مثير ات عيانية، وقالت دراسة دنيا

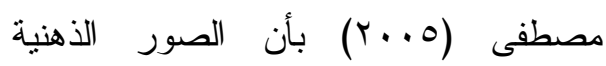
البصرية هى أكثر تأثير الدى الاطفال وأبقى بان الدئ أثز ا. بعد عرض الإطار النظري وما أثنارت إلية الجهود الأدبية فيما يتعلق بمتغير ات الدراسة

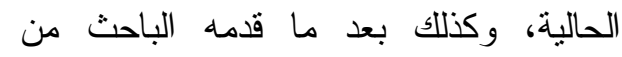

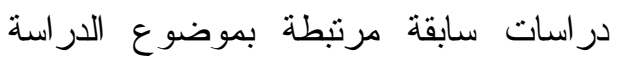


وأيضا الاستفادة من الدراسات

السابقة التى تتاولت التصور العقلي و الصور

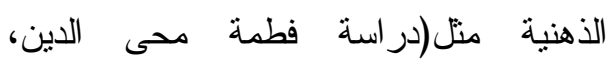

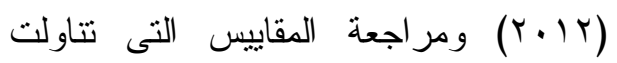

الصور الذهنية منل مقياس المهارات

الحسحركية للاطفال اضطر اب التوحد (منه منه

الله، V. V)، و و مقياس المفاهيم الادر اكية

لدى الأطفال ذوى اضطراب التوحد (شيماء

حسانين، r ( • (r).

وصف المقياس:

هو مقياس يتكون من (§ᄉ) مفردة

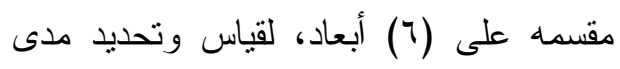

القصور في الصور الذهنية لدي أطفال

اضطر اب التوحد، ويشتمل كل بعد على قياس

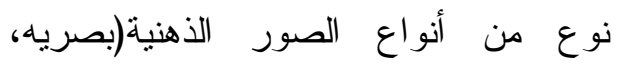

سمعسة ،لمسيه، شميه، تذوقيه، حركية)، وهو

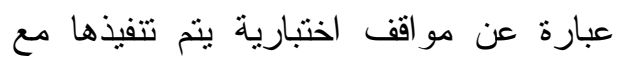

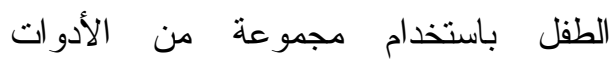

المحددة.

وللتحقق من الشروط السيكومترية للمقياس قام

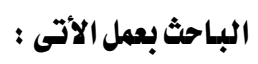

أولاً : الصلدق احثق

$$
\text { أ. أو صدق المحكمين }
$$

تم عرض المقياس على (•(1) من أساتذة علم النفس والصحة النفسية وذلك للتعرف على أر ائهم حول مناسبة صياغة العبار ات و المحتوى لقياس الصور الذهنية لأطفال
تتكون عينة الدراسة من (0) أطفال

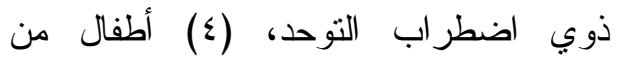

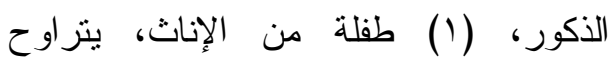
أعمار هم بين (ع: 7 7) سنوات، من وحدة الإن،

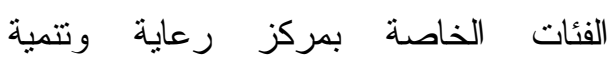

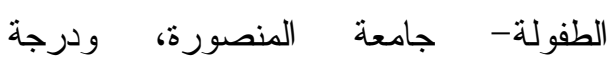

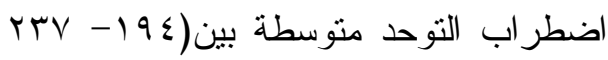

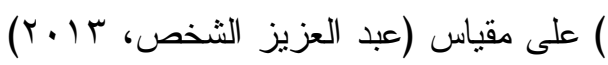

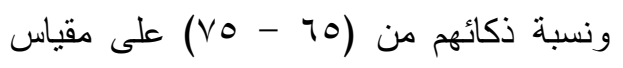
ستانفورد بينيه(الصورة الخامسة). أدوات اللدراسة: 1- مقياس تشخيص اضطر اب التوحد

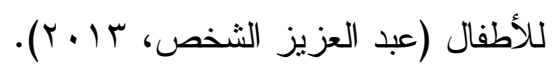
r- مقياس ستانفورد بينيه لقياس الذكاء (الصورة الخامسة) ترجمة و وتقنين

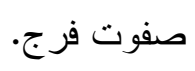
r- مقياس الصور الذهنية لأطفال اضطر اب التوحد (إعداد الباحث). ع- البرنامج التدريبي •(اعداد الباحث) مقياس الصور الذهنية لأطفال اضطراب التوحلد :

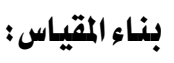
قام الباحث بالاطلاع على الأطر

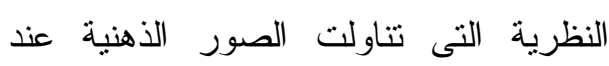
الأطفال منل كتاب التصور العقلي (دينا مصطفي، • • (Y) وكتاب الذاكرة (مصطفي

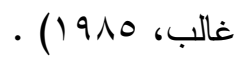



التعديلات المطلوبة ، ويوضح جدول (1 )
اضطر اب التوحد وقد بلغت نسبة الاتفاق
تعديلات المقياس:
، وتم إجراء
بين المحكمين (،^\%)

\section{جدول (1 )}

تعديلا ت المقياس بناء على أراء السادة المحكمين

\begin{tabular}{|c|c|c|c|c|}
\hline الوصف & بعد التعديل & قبل التعديل & البنود & الأبعاد \\
\hline تعديل & 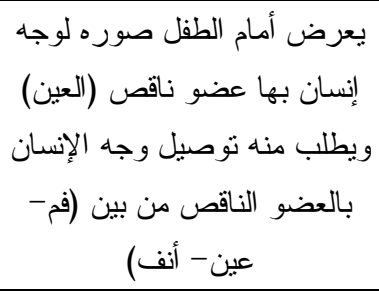 & يعرض أمام الطفل صوره لوجه إنسان & $\varepsilon$ & الصور الذهنية \\
\hline تعديل & تعرضئل أمام الطفل ثلاث صور & يعطى الطفل صورة سيارة ويطلب & 1. & \multirow{3}{*}{ الصور الذهنية } \\
\hline تعديل & 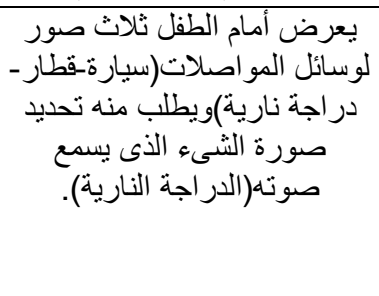 & 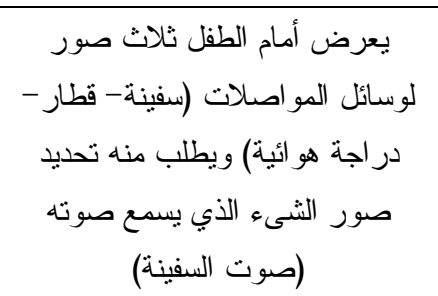 & 11 & \\
\hline تعديل & 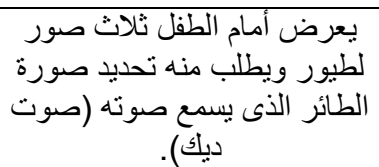 & يعطي الطف صورة (ديك) ويطلب & 10 & \\
\hline تعديل & 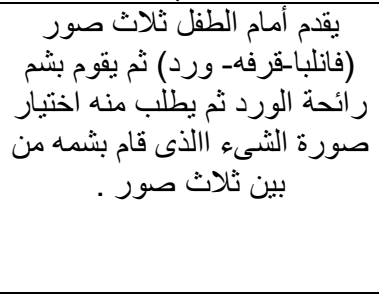 & 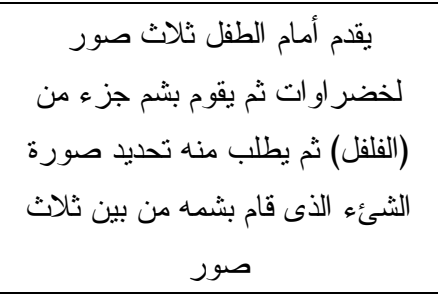 & $r q$ & الصور الذهنية \\
\hline تعديل & 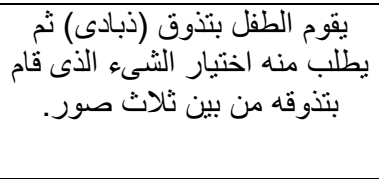 & يقوم الطفل بتذوق لبان بطعم الفر اولة & $r \wedge$ & الصور الذهنية \\
\hline
\end{tabular}




\begin{tabular}{|c|c|c|c|c|}
\hline حذف & & يطلب من الطفل تقليد حركات الجزار & $\varepsilon r$ & \\
\hline حذف & - & يطلب من الطفل اختبار الرياضة المعلم باللعب (بكرة القدم) ثم & $\leqslant 0$ & الصور الذهنية \\
\hline
\end{tabular}

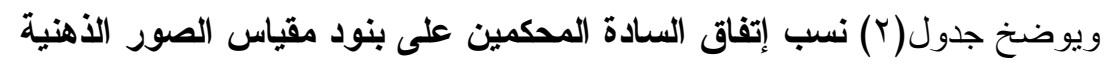

جدول (Y): نسب إتفاق المحكمين بنود على مقياس الصور الأهنية

\begin{tabular}{|c|c|c|c|c|c|c|c|}
\hline نسبة اتفاق & البند & & & نسبة اتفاق & البند & & \\
\hline$\% 1 \ldots$ & 9 & \multirow{8}{*}{ الذهنية } & \multirow{8}{*}{ الصمور } & $\% 1 .$. & 1 & \multirow{8}{*}{ الذهنية } & \multirow{8}{*}{ البصرية } \\
\hline$\% q$. & 1. & & & $\% 1 .$. & $r$ & & \\
\hline$\% q$. & 11 & & & $\% 1 .$. & $r$ & & \\
\hline$\% 1 \ldots$ & Ir & & & $\% \wedge$. & $\varepsilon$ & & \\
\hline$\% 1 \ldots$ & 14 & & & $\% 1 .$. & 0 & & \\
\hline$\% 1 \ldots$ & $1 \leqslant$ & & & $\% 1 .$. & 7 & & \\
\hline$\% 1 \ldots$ & 10 & & & $\% 1 \ldots$ & V & & \\
\hline$\% 1 \ldots$ & 17 & & & $\% 9$. & $\wedge$ & & \\
\hline$\% 1 \ldots$ & ro & \multirow{8}{*}{ الذهنية } & \multirow{8}{*}{ الثمية } & $\% \wedge$. & IV & \multirow{8}{*}{ الذ هنية } & \multirow{8}{*}{ اللمسية } \\
\hline$\% 1 \ldots$ & r & & & $\% \wedge$. & 11 & & \\
\hline$\% 1 \ldots$ & rV & & & $\% 1 .$. & 19 & & \\
\hline$\% 1 \ldots$ & rᄉ & & & $\% 9$. & r. & & \\
\hline$\% q$. & rq & & & $\% 1 .$. & r) & & \\
\hline$\% 1 \ldots$ & r. & & & $\% 1 \ldots$ & rT & & \\
\hline$\% 1 \ldots$ & rI & & & $\% 1 \ldots$ & rT & & \\
\hline$\% 1 \ldots$ & rT & & & $\% 1 .$. & $T \varepsilon$ & & \\
\hline$\% q$. & $\varepsilon 1$ & \multirow{7}{*}{ الذهنية } & \multirow{7}{*}{ الصركية } & $\% 1 .$. & זי & \multirow{7}{*}{ الأهنية } & \multirow{7}{*}{ التذوقية } \\
\hline$\% \vee$. & $\varepsilon r$ & & & $\% 1 \ldots$ & $\Gamma \varepsilon$ & & \\
\hline$\% q$. & $\varepsilon r$ & & & $\% 1 .$. & ro & & \\
\hline$\% q$. & $\varepsilon \varepsilon$ & & & $\% 1 .$. & דr & & \\
\hline$\% \vee$. & $\leq 0$ & & & $\% q$. & rv & & \\
\hline$\% q$. & $\leq 7$ & & & $\% 9$. & rᄉ & & \\
\hline$\% q$. & $\varepsilon V$ & & & $\% 1 \ldots$ & rq & & \\
\hline
\end{tabular}




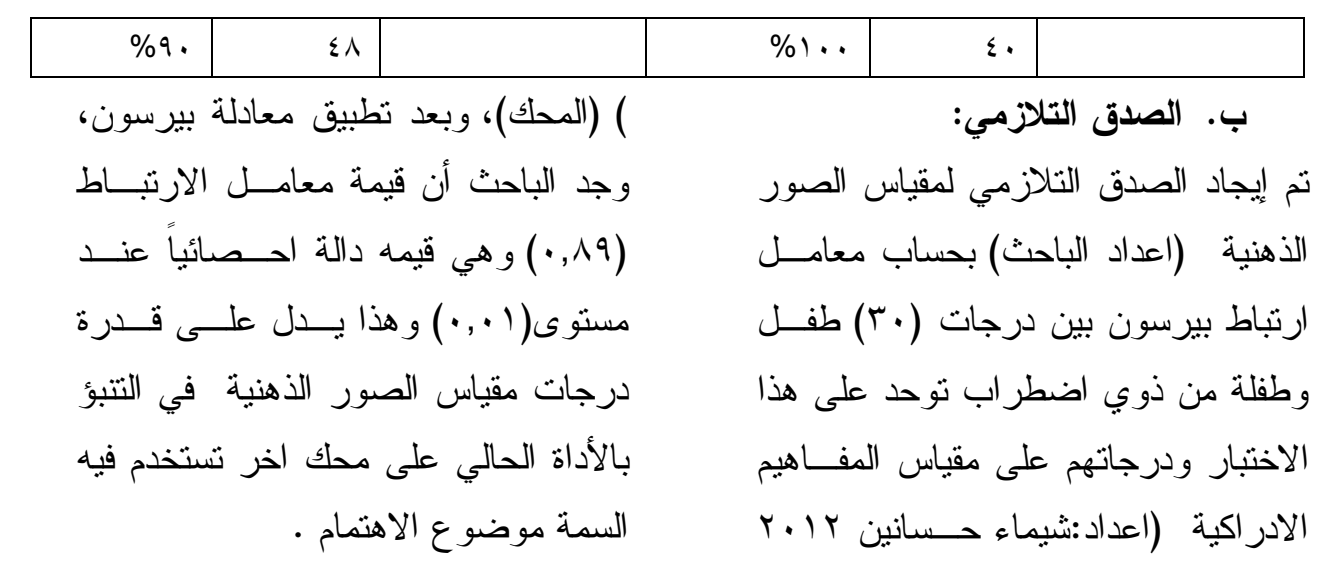

جدول (r)

يوضح معامل الإرتباط أبعاد مقياس الصور الذهنية بأبعاد مقياس المفاهيم الادراكية

\begin{tabular}{|c|c|c|c|c|c|c|}
\hline الارجة & التذوقى الإدر & الشمى الإدر الك & اللمسي الإدراك & السمعي الإدراك & البصرى الإدر اك & الإدراك الحسي الصور \\
\hline 0.87 & 0.69 & 0.81 & 0.79 & 0.69 & 0.65 & الصور الذهنية البصرية \\
\hline 0.82 & 0.75 & 0.68 & 0.74 & 0.66 & 0.66 & الصور الذهنية السمعية \\
\hline 0.79 & 0.76 & 0.69 & 0.78 & 0.75 & 0.67 & الصور الذهنية اللمسية \\
\hline 0.80 & 0.79 & 0.72 & 0.61 & 0.75 & 0.61 & الصور الذهنية الثمية \\
\hline 0.84 & 0.81 & 0.77 & 0.68 & 0.77 & 0.67 & الصور الذهنية التذوقية \\
\hline 0.79 & 0.77 & 0.78 & 0.69 & 0.68 & 0.77 & الصور الذهنية الحركية \\
\hline 0.89 & 0.84 & 0.83 & 0.82 & 0.78 & 0.82 & الدرجة الكلية \\
\hline
\end{tabular}

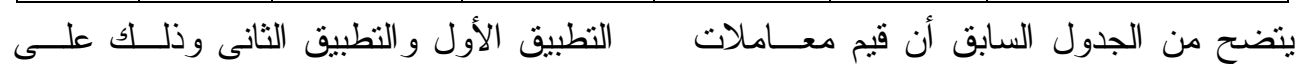

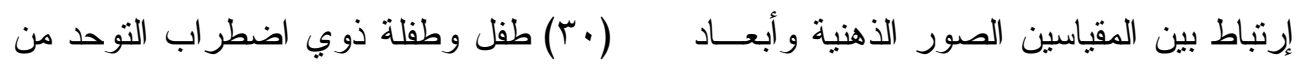

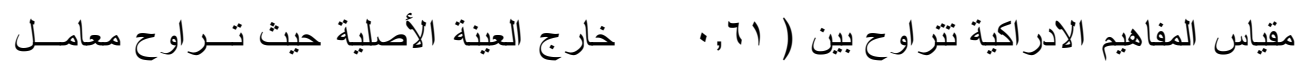

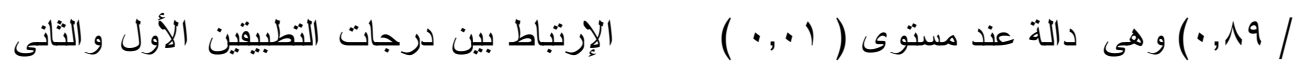

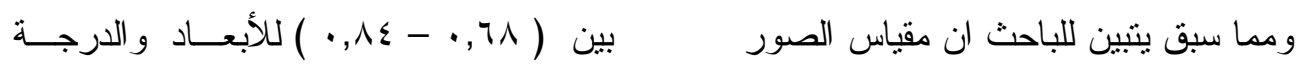

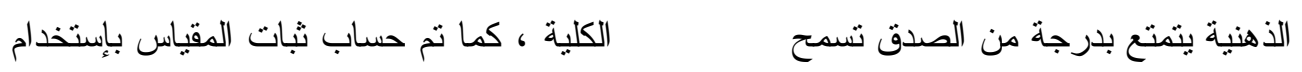

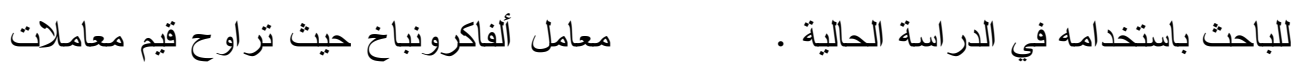

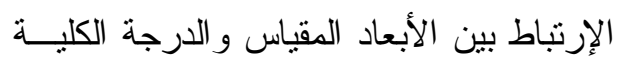

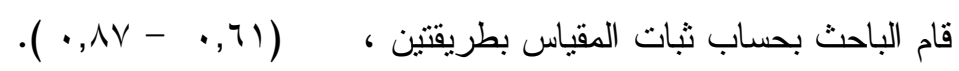
إعادة الإختبار بفارق زمنى أســبو عين بـين بـين 
جدول ( ) ( )

قيم معاملات ثبات أبعاد المقياس والارجة الكلية بطريقتي إعادة التطبيق ومعامل ألفا كرونباخ

\begin{tabular}{|c|c|c|}
\hline إعادة الإختبار & ثبات الفاكرونباخ & ( \\
\hline$\cdot, V Y T$ & - Vor & الصور الذهنية البصرية \\
\hline$\cdot, 794$ & $\cdot, 7 \leqslant 0$ & الصور الذهنية السمعية \\
\hline$\cdot, \mathrm{v}, 1$ &., $\mathrm{VO} 1$ & الصور الذهنية اللمسية \\
\hline ·, & $\cdot ., 71 \%$ & الصور الذهنية الثنمية \\
\hline$\cdot, 799$ &., $7 Y \Lambda$ & الصور الذهنية التذوقية \\
\hline$\cdot, V \cdot Y$ & $\cdot, \mathrm{V} O \varepsilon$ & الصور الذهنية الحركية \\
\hline$\cdot, \wedge \leq 0$ & $\cdot, \wedge Y \bar{Y}$ & الإختبار ككل \\
\hline
\end{tabular}

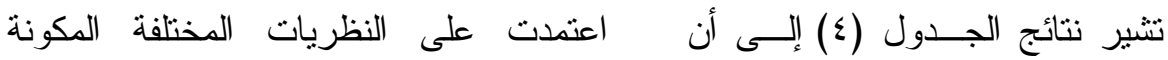

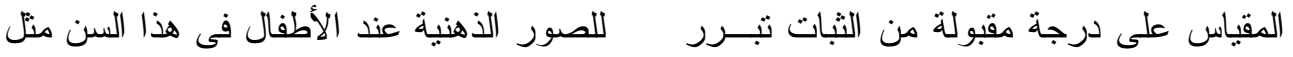

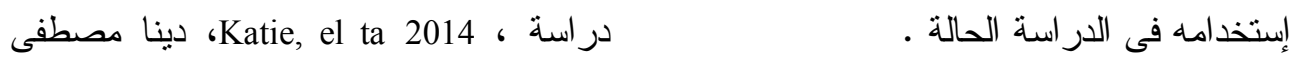

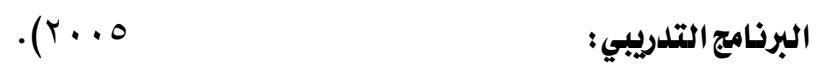

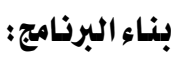

لقد اعتمد الباحث عند بناء البرنامج

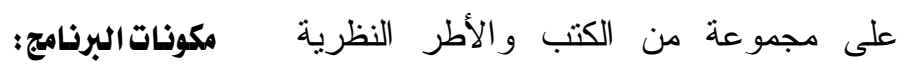

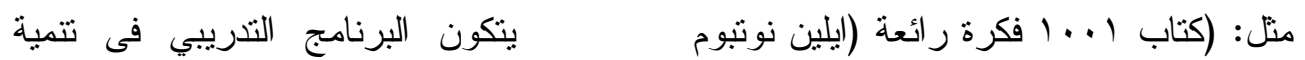

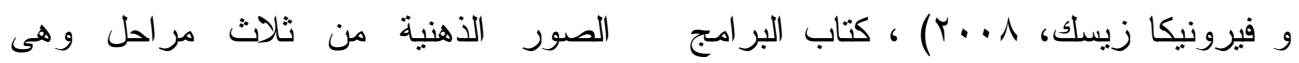

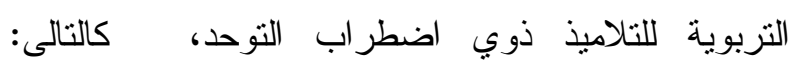

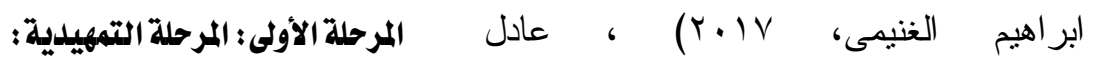

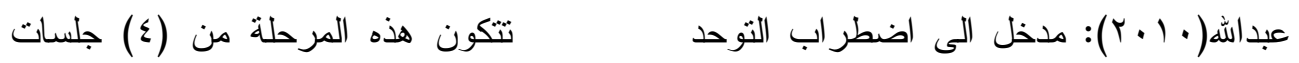

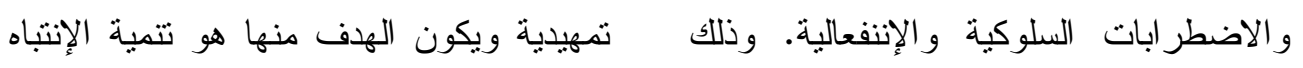

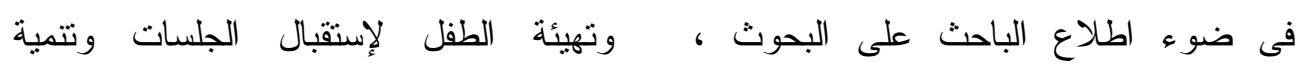

وتوظيفها بحيث تخدم تتمية الصور الذهنية الر الر ابطة الوجدانية بين الطفل وبين الباحث،

من خلال الإطلاع على الدراسات النى المرحلة الثانية:مرحلة التلدربب: 


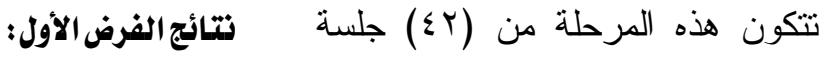

$$
\text { بنص الفرض الأول على أنه: }
$$

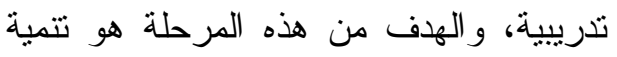

"توجد فروق دالة احصائيا بين متوسطات الأن

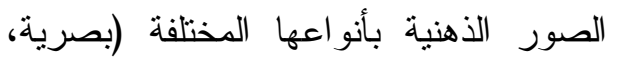
رتب درجات أطفال المجموعة التجريبية سمعية، لمسية، شمية، تذوقية، حركية. وقام على مقياس الصور الذهنية في القياس القبلي و البعدي لصالح القياس البعدي"

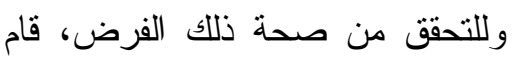

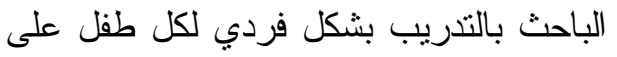
حدة لمر اعاة خصائص الأطفال و إحتياجاتهم.

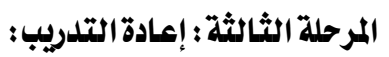

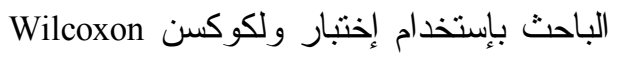

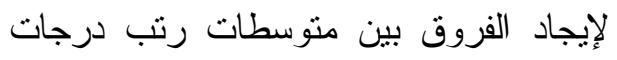
أفر اد المجموعة التجريبية قبل تطبيق البرنامج

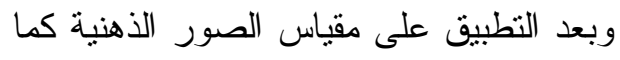

$$
\text { يتضح فى جدول(0). }
$$

نتائج الدراسة ؛

\begin{tabular}{|c|c|c|c|c|c|c|c|c|}
\hline \multicolumn{2}{|c|}{ حجم التأثُر } & \multirow{2}{*}{ الدالاهة } & \multirow{2}{*}{$\mathbf{Z}$} & \multirow{2}{*}{ الرتبوع } & \multirow{2}{*}{ متوسط } & \multirow{2}{*}{ العدد } & \multirow{2}{*}{ القبلى-البعدي } & \multirow{2}{*}{ الأبعاد } \\
\hline الحجم & $\mathbf{R}$ & & & & & & & \\
\hline \multirow{4}{*}{ كبير } & \multirow{4}{*}{0.639} & \multirow{4}{*}{ في إتجاه } & \multirow{4}{*}{2.023} & - & - & - & الرتب السالبة & \multirow{4}{*}{ الصور الذهنية } \\
\hline & & & & 15 & 3 & 5 & الرتب الموجبة & \\
\hline & & & & & & - & الرتب المتساوية & \\
\hline & & & & & & 5 & إجمالى & \\
\hline \multirow{4}{*}{ كبير } & \multirow{4}{*}{0.642} & \multirow{4}{*}{ في البقاس } & \multirow{4}{*}{2.032} & - & - & - & الرتب السالبة & \multirow{4}{*}{ الصور الذهية } \\
\hline & & & & 15 & 3 & 5 & الرتب الموجبة & \\
\hline & & & & & & - & الرتب المتساوية & \\
\hline & & & & & & 5 & إجمالى & \\
\hline \multirow{4}{*}{ كبير } & \multirow{4}{*}{0.642} & \multirow{4}{*}{ في إلجاه } & \multirow{4}{*}{2.032} & - & - & - & الرتب السـالبة & \multirow{4}{*}{ الصور الذهنية } \\
\hline & & & & 15 & 3 & 5 & الرتب الموجبة & \\
\hline & & & & & & - & الرتب المتساوية & \\
\hline & & & & & & 5 & إجمالى & \\
\hline \multirow{4}{*}{ كبير } & \multirow{4}{*}{0.639} & \multirow{4}{*}{ في إلجاه } & \multirow{4}{*}{2.023} & - & - & - & الرتب السالبة & \multirow{4}{*}{ الصور الذهنية } \\
\hline & & & & 15 & 3 & 5 & الرتب الموجبة & \\
\hline & & & & & & - & الرتب المتساوية & \\
\hline & & & & & & 5 & إجمالى & \\
\hline \multirow{4}{*}{ كبير } & \multirow{4}{*}{0.642} & \multirow{4}{*}{ في البقان } & \multirow{4}{*}{2.032} & - & - & - & الرتب السالبة & \\
\hline & & & & 15 & 3 & 5 & الرتب الموجبة & الصور الذهنية \\
\hline & & & & & & - & الرتب المتساوية & التذوقية \\
\hline & & & & & & 5 & إجمالى & \\
\hline كبير & 0.639 & في إتجاه & 2.023 & - & - & - & الرتب السالبة & الصور الأهنية \\
\hline & & القياس & & 15 & 3 & 5 & الرتب الموجبة & الحركية \\
\hline & & البعدي & & & & - & الرتب المتساوية & \\
\hline
\end{tabular}
جدول (ه): الفروق بين متوسطات رتب درجات أفراد المجموعة التجريبية، قبل تطبيق البرنامج 


\begin{tabular}{|c|c|c|c|c|c|c|c|c|}
\hline \multicolumn{2}{|c|}{ حجم التأثير } & \multirow{3}{*}{ الإلاة } & \multirow{3}{*}{$\mathbf{Z}$} & \multirow{3}{*}{ الرتبوع } & \multirow{3}{*}{ متوسط الرتب } & \multirow{2}{*}{ العدد } & \multirow{2}{*}{ القبلى-البعدي } & \multirow{3}{*}{ الأبعاد } \\
\hline الحجم & $\mathbf{R}$ & & & & & & & \\
\hline & & & & & & 5 & إجمالى & \\
\hline \multirow{4}{*}{ كبير } & \multirow{4}{*}{0.642} & \multirow{4}{*}{ في القياس } & \multirow{4}{*}{2.032} & - & - & - & الرتب السالبةٌ & \multirow{4}{*}{ الدرجة الكلية } \\
\hline & & & & 15 & 3 & 5 & الرتب الموجبة & \\
\hline & & & & & & - & الرتب المتساوية & \\
\hline & & & & & & 5 & إجمالى & \\
\hline
\end{tabular}

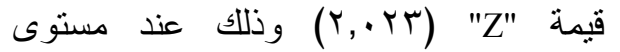
معنوية (0 . . • ) بين منوسطات رثب درجات أفر اد المجموعة التجريبية، قبل ت تطبيق البرنامج وبعد التطبيق فى إتجاه القياس البعدي، الصور الأهنية التذوقية توجد فروق ذات دلالة إحصائية بين كل من (التطبيق

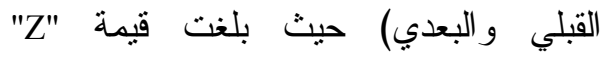

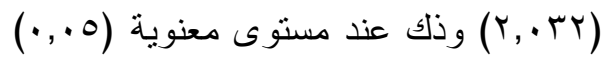
بين متوسطات رتب درجات أفر اد المجموعة التجريبية، قبل تطبيت البرنامج وبعد التطبيق فى إتجاه القياس البعدي، الصور الأهنية الحركية نوجد فروق ذات دلالة إحصائية بين كل من (التطبيق القبلي و البعدي) حيث بلغت

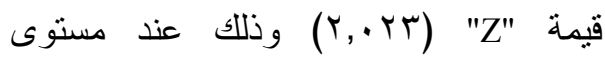
معنوية (0, •) بين متوسطات رتب درجات

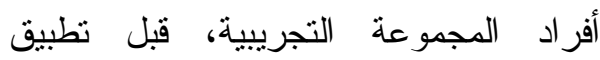
البرنامج وبعد التطبيق فى إتجاه القياس البعدي،إجمالى مقياس الصور الأهنية توجد فروق ذات دلالة إحصائية بين كل من من (التطبيق القبلي و البعدي) حيث بلغت قيمة (ه" (0., ) بين متوسطات رتب درجات أفراد
الصور الاهنية البصرية توجد فروق ذات دلالة إحصائية بين كل من (التطبيق القبلي و البعدي) حيث بلغت قيمة "Z" (T, (Y) وذللك عند مستوى معنوية (0., •) بين متوسطات رتب درجات أفراد المجموعة التجريبية، قبل تطبيق البرنامج وبعد التطبيق فى إتجاه القياس البعدي، الصور الاهنية السمعية نوجد فروق ذات دلالة إحصائية بين كل من (التطبيق القبلي و البعدي) حيث بلغت

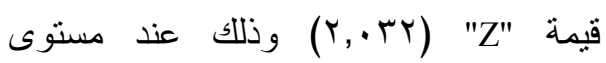
معنوية (0 . . • ) بين متوسطات رتب درجات أفراد المجموعة التجريبية، قبل ت تطبيق البرنامج وبعد التطبيق فى إتجاه القياس البعدي، الصور الأهنية اللمسية توجد فروق ذات دلالة إحصائية بين كل من (التطبيق

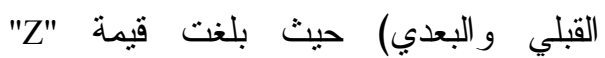

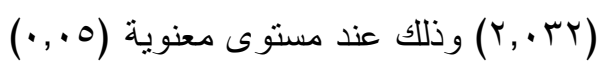
بين متوسطات رتب درجات أفر اد المجموعة التجريبية، قبل تطبيق البرنامج وبعد التطبيق فى إتجاه القياس البعدي، الصور الاهنية الشمية توجد فوق ذات دلالة إحصائية بين كل من التطبيق القبلي و البعدي) حيث بلغت 
اضطراب التوحد فى عملية الندريب أكثر من غيرها من أنواع الصور الذهنية الكربي الأخرى. نتائج الفرض الثاني: ينص الفرض الثاني على أنه: "ال توجد فروق دالة احصائيا بين متوسطات رتب درجات أطفال المجموعة التجريبية على مقياس الصور الأهنية في القياسين البعدي والتتبعي" وللانحقق من صحة ذلك الفرض، قام الباحث بإستخدام إختبار ولكوكسن Wilcoxon رتب درجات أفراد المجموعة التجريبية فى لئي

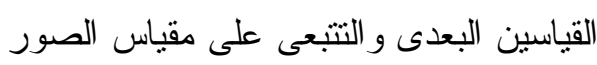

الذهنية كما يتضح فى جدول (؟).
المجموعة التجريبية، قبل تطبيق البرنامج

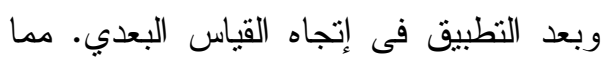
يدل على الفارق الكبير بين كل من (التطبيق التيقاه القبلي و البعدي) لمقياس الصور الذهنير بنانية.

\section{مناقشة نتائج الفرض الأول:}

جاء نتائج الفرض الأول متفقه مع دراسه

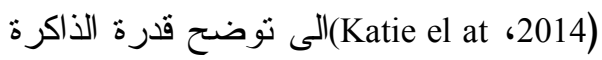
على استرجاع الصور الذهنية لاى الأطفال الذين يعانون من اضطر اب التوحد وتنفق مع الأطع

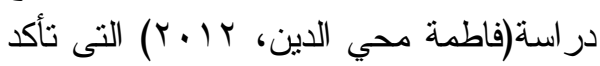

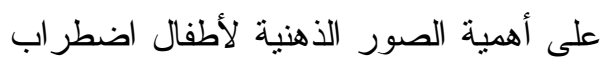
التوحد حيث ودور التدريب فى تتمية الصور التطرال

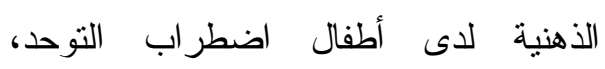
وأظهرت الدراسة أن التحسن كان كبيرا

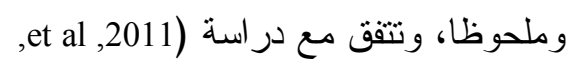
(Zeffiro

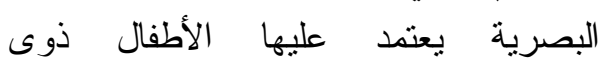
جدول (†): الفروق بين متوسطات رتب درجات أفراد المجموعة التجريبية فى القياسيين البعي والتبعيى

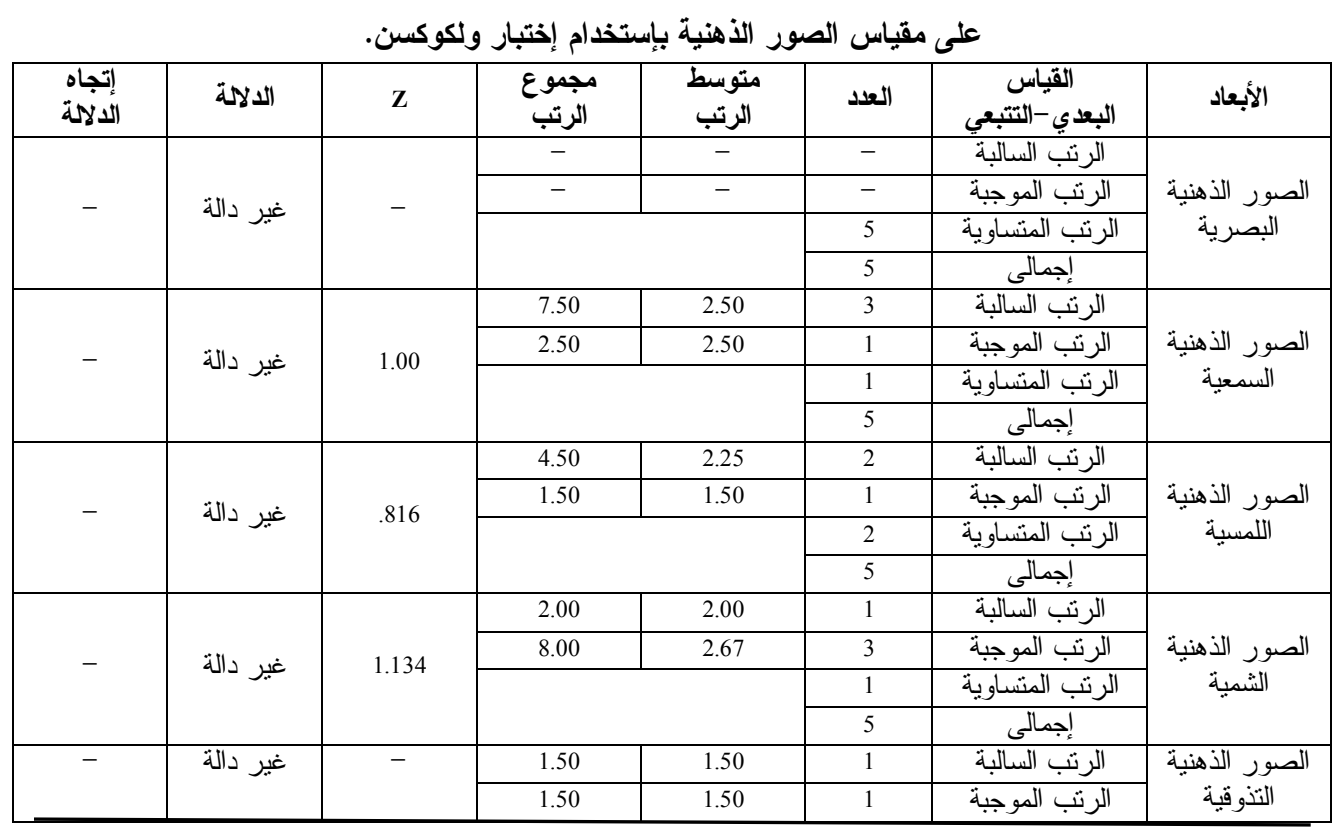




\begin{tabular}{|c|c|c|c|c|c|c|c|}
\hline إلتجاه & الدلالة & $\mathbf{Z}$ & الزتبوع & متوسط & العدد & البعدي-التيتبعي & الأبعاد \\
\hline & & & & & 3 & الرتب المتساوية & \\
\hline & & & & & 5 & إجمالى & \\
\hline \multirow{4}{*}{-} & \multirow{4}{*}{ غير دالة } & \multirow{4}{*}{1.00} & 1.00 & 1.00 & 1 & الرتب السالبة & \multirow{4}{*}{ الصور الذهنية } \\
\hline & & & - & - & - & الرتب الموجبة & \\
\hline & & & & & 4 & الرتب المتساوية & \\
\hline & & & & & 5 & إجمالى & \\
\hline \multirow{4}{*}{-} & \multirow{4}{*}{ غير دالة } & \multirow{4}{*}{1.134} & 8.00 & 2.67 & 3 & الرتب السالبة & \multirow{4}{*}{ الدرجة الكلية } \\
\hline & & & 2.00 & 2.00 & 1 & الرتب الموجبة & \\
\hline & & & & & 1 & الرتب المتساوية & \\
\hline & & & & & 5 & إجمالى & \\
\hline
\end{tabular}

(0.01) عند مسنوى الدالة

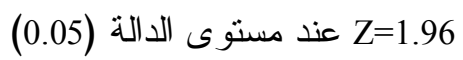

دالة، لا نوجد فروق ذات دلالة إحصائية بين

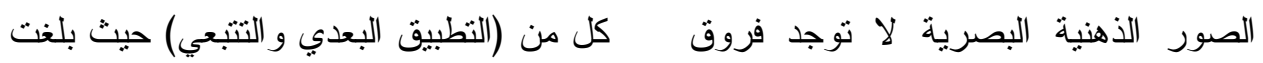

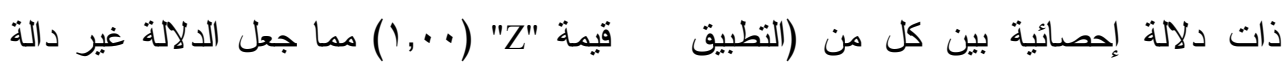

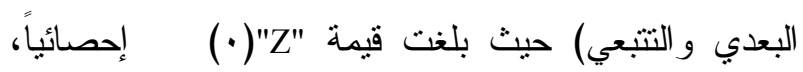

لا نوجد فروق ذات دلالة إحصائية

مما جعل الدلالة غير دالة، أماالصور الذهنية

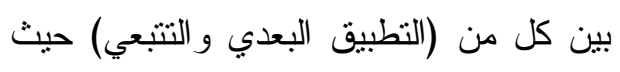

السمعية فلا نوجد فروق ذات دلالة إحصائية

بلغت قيمة "Z" (عاب ا, ( ) مما جعل الدلالة

بين كل من (التطبيق البعدي و التتبعي) حيث غير دالة إحصائياً.

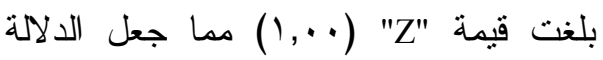

\section{توصيات الدراسة:}

مبث برامج التوعية عبر شبكات الإذاعة و التلفزيون و الجهات المختلفة بأهمية الصور الذهنية للأطفال ذوي

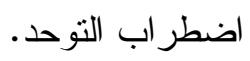

تدريب العاملين فى مجال التربية

غير دالة.بالنسبة الصور الذهنية اللمسية لا

توجد فروق ذات دلالة إحصائية بين كل من دن

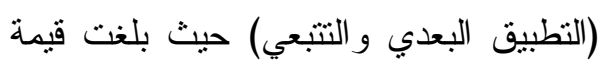

"Z"

الصور الذهنية الثمية لا توجد فروق ذات التمل التهات

الخاصة على فنيات و أساليب بناء

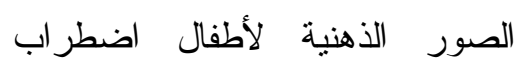

$$
\text { التوحد. }
$$

دلالة إحصائية بين كل من (التطبيق البعدي

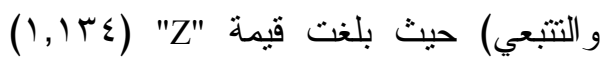

مما جعل الدلالة غير دالة، الصور الذهنية

$$
\text { التذوقية }
$$

\section{البحوث المقترحة :}

1 - إجر اء در اسة لمعرفة مهار ات مو اجهة

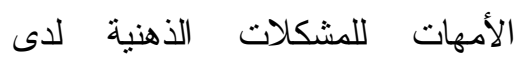

لا توجد فروق ذات دلالة إحصائية

بين كل من (التطبيق البعدي و التتبعي) حيث

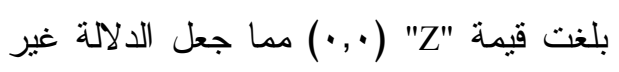


الأطفال المعاقين ذهنياً من فئة القــابلين

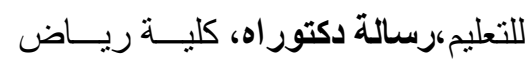
الأطفال، قسم العلوم النفـسية :جامعـــة القاهرة.

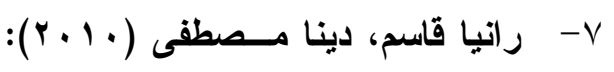
اضطر ابات النمو الثامل و المتلازمات لاى الأطفال، القــاهرة: دار الجامعــة الجديدة.

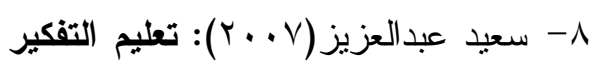

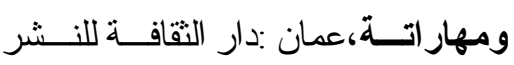

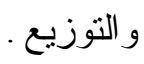

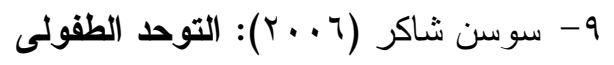
أسبابه، خصائصه، تثخيصه، علاجه،

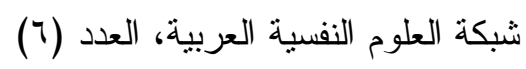

$$
\text { المكتبة الإلكترونية . }
$$

• 1 - شيماء حسانين (Y ( • Y): تتمية المفاهيم

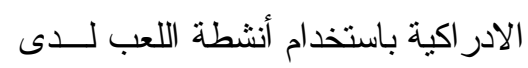

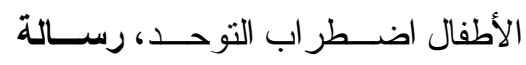

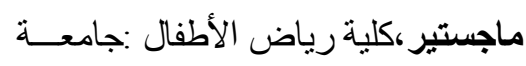

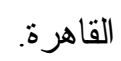

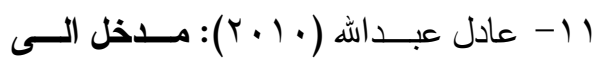

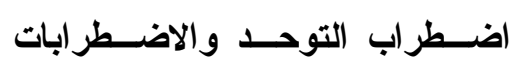

السلوكسية والإنفعاليـــة، القـــاهرة :دار

$$
\text { الرشاد. }
$$

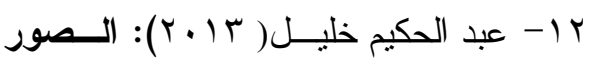

الأهنية وحمــلات العلاقة الــات العامــة،

$$
\text { القاهرة : الدار العربية للنشر و التوزيع. }
$$

أطفالهن ذوي اضطراب التوحد بين

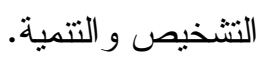

r- در اسة أثز التدخل المبكر فى نتمية

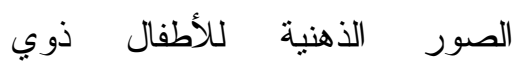

$$
\text { متلازمة(اسبرجر ). }
$$

\section{المراجـــ :}

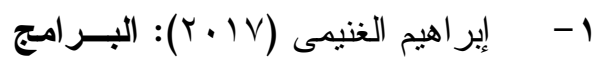

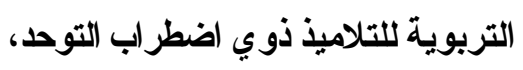

الرياض :دار الزهر اء للنشر و التوزيع.

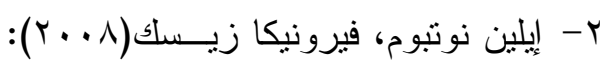

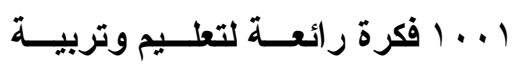

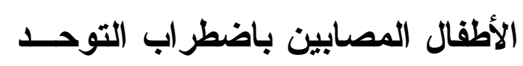

كترجمة الناثر ، الرياض :مكتبة جرير.

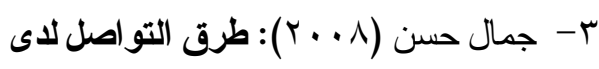

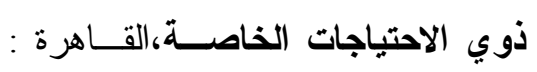

$$
\text { الطبري للطباعة. }
$$

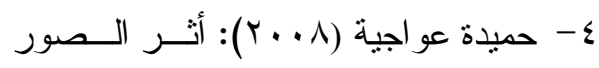

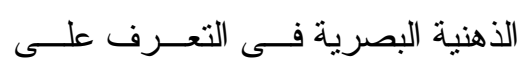

الكلمات المكتوبة لدى الحبسى ،رســالة

ماجسـتير منـشورة، كليــة العلــوم

الاجتماعية و الإنسانية :جامعة الجز ائر .

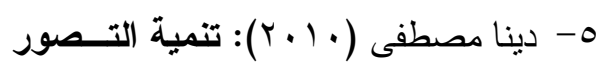

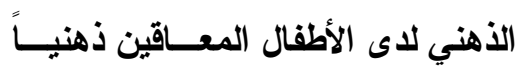
القابلين للتعليم، الاز اريطة :دار الجامعة

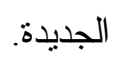

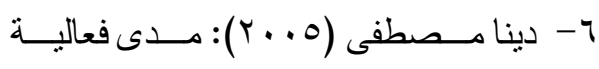

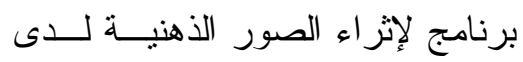




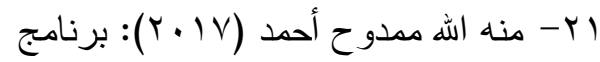

قائم على توظيف الخامات المـستهلكة

لتحسـين المهــار ات الحسـسمركية

لإضطر اب الذاتوتية، رسالة ماجستير ،

كلية التزبية للطفولة المبكرة، قسم العلوم

$$
\text { النفسية :جامعة القاهرة. }
$$

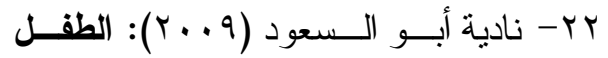

التوحدي فى الأســـرة، الأســكندرية،

مؤسسة حورس الدولية للنشر و التوزيع.

23- Byrd, R. Sage, A., Keyzer, J., Shefeling, R., Gee, K. a Enders, K (2000): Report of the Legislature on the Principle Findings from the Epidemiology of Autism in California (A comprehensive pilot study), J. Autism, Disorder, 25(3), 312-410.

24- Exkorn, K.S. (2005): The Autism Source Book: Everything you Need to Know about Diagnosis, Treatment, Coping, and Healing. Regan Books. New York.

25- Halloun, D. (2000): Student Resources for Learning Introductory Physics. American.

26- Kamio, y. B Ishisaka, Y. (2004): Psychiatric Comorbidity in Children Adolescents with Autism \& Mental Retardation. Japanese Journal of children Adolescents psychiatric.

27- Katie, L. ; Marina, C. ; Elizabeth, J. ; Dermot, M.(2014): Mental imagery scanning in autism spectrum disorder. Research in Autism Spectrum Disorders, 8(10), 1416 1423.

28- Kendall, C. (2002): Childhood Disorders. East Sussex Psychology Press Publishers. UK.

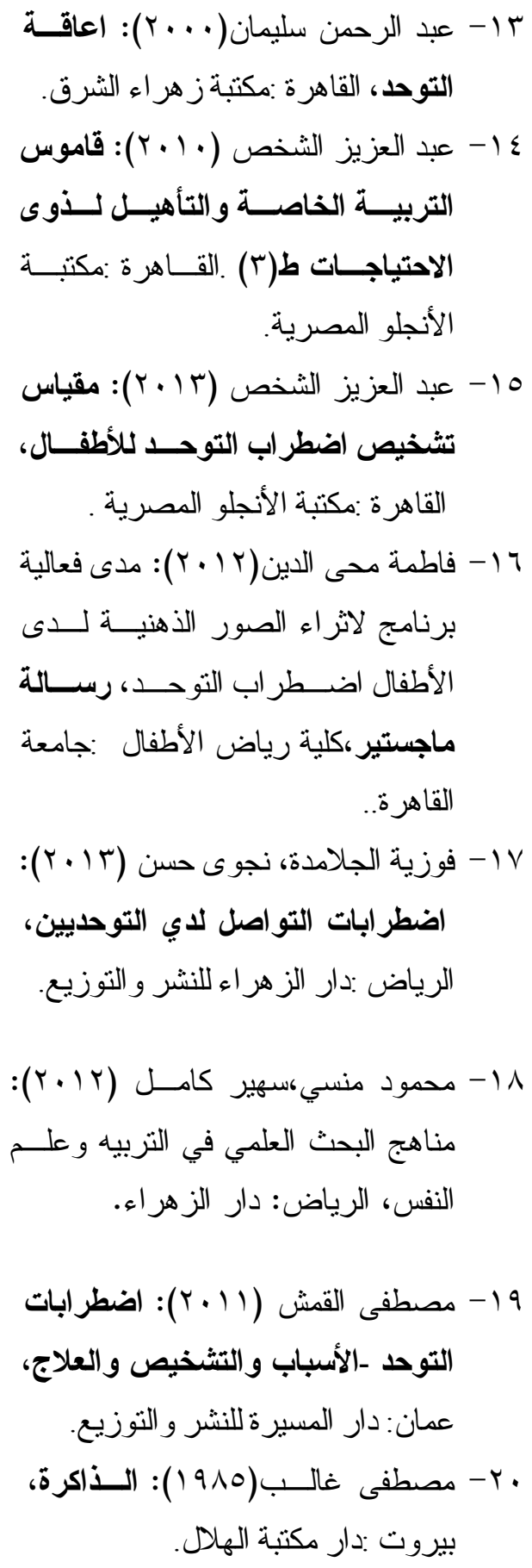


32- Piaget et B, Inhelder. (1975): The Image Mentales in Trail de Sychologic Experimental, Paris: P.V.F.P, Vol.III.

33- Watson, A., (1991): Using Representation Comprehension Production of Actions with Imagined Objects. USA.

34- Zeffiro, T. A.; Soulieres, I.; Girard, M. L.; Mottron, L (2011): Enhanced Mental Image Mapping in Autism, Neuropsychology, 49 (5), 848- 857.
29- Matlin, M., (2005): Cognition, Sixth Edition, tohan wiley \& Sons, Inc.

30- Muller, R.A. (2007): The Study of Autism as Distributed Disorder, Ment Retard Dev Disabil Res. Rev, 13(1), 85-95.

31- Oliver, E. (2002): Mental imagery ability in high-and low performance collegiate basketball players. Unpublished ph. D. Dissertation, Boston University. 